\title{
Relationship between the movements of the mouthparts of the bamboo powder-post beetle Dinoderus minutus and the generation of acoustic emission
}

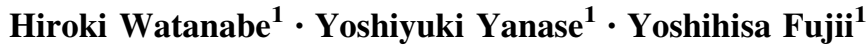

Received: 4 August 2015/Accepted: 28 October 2015/Published online: 18 November 2015

(C) The Japan Wood Research Society 2015

\begin{abstract}
In order to apply acoustic emission (AE) monitoring to the non-destructive and continuous analysis of the feeding biology of the bamboo powder-post beetle Dinoderus minutus inside bamboo culms, it is essential to clarify the relationship between their feeding activity and $\mathrm{AE}$ generation. In this study, the behavior of the larva and adult of D. minutus in a madake (Phyllostachys bambusoides) specimen was directly observed by a microscope, while $\mathrm{AE}$ measurement of the specimen attached to an $\mathrm{AE}$ sensor $(150 \mathrm{kHz}$ resonant frequency) was conducted simultaneously. The mandibles of the larva or the adult exhibited "chewing movements" when it was in feeding activity. AE hits were detected as the larva or adult chewed the specimen with its mandibles. Under the measurement conditions employed, chewing movements of the mandibles that produced AE hits accounted for $26-42 \%$ of the total chewing movements for larvae, and $27-43 \%$ for adults. On the other hand, when the larva or adult was not chewing the specimen, almost no AE hits were detected. Therefore, the generation of $\mathrm{AE}$ corresponded to the chewing movements of the mandibles of D. minutus.
\end{abstract}

Part of this paper was presented at the 26th Annual Meeting of the Japanese Society of Environmental Entomology and Zoology (Nagasaki, Japan, 2014) and the 65th Annual Meeting of the Japan Wood Research Society (Tokyo, Japan, 2015).

Electronic supplementary material The online version of this article (doi:10.1007/s10086-015-1525-4) contains supplementary material, which is available to authorized users.

Hiroki Watanabe

watanabe@h3news1.kais.kyoto-u.ac.jp

1 Graduate School of Agriculture, Kyoto University, Kitashirakawaoiwake-cho, Sakyo-ku, Kyoto 606-8502, Japan
Keywords Powder-post beetle - Dinoderus minutus . Bamboo - Acoustic emission - Microscopy

\section{Introduction}

Bamboo has been widely used in Japan as a building material for decorative elements in traditional wooden houses, and for furniture or craft products. However, its vulnerability to insect attack limits its use, and thus measures to protect bamboo materials from insects are necessary. This is especially important when bamboo is employed as laths that contribute to the strength of clay walls in traditional wooden houses. Because bamboo laths are covered with clay, insect damage is not easily detected and the damage may become widespread, making the laths brittle and causing the wall to lose strength.

The bamboo powder-post beetle Dinoderus minutus (Fabricius) (Coleoptera: Bostrichidae) is one of the most significant pests of felled bamboo in Japan, whether it is in storage or in use [1-3]. Mated adults enter bamboo from the cut surfaces, especially the end surfaces of culms, and oviposit inside. The hatched larvae develop by boring into and feeding on the parenchyma along the fibers near the inner surface of culms and undergo ecdysis four times before pupation. The adults also feed on bamboo after eclosion to obtain nutrients and leave via an exit hole to mate. D. minutus has one to four broods per year in Japan, and adults are seen from March to November [2,3].

One possible method of insect control for bamboo in storage or in use is to treat the bamboo with chemical insecticide to prevent insect attack and to exterminate insects which may be active inside, but it is not always recommendable considering both the expense and impacts on human health and the environment. The desirable 
process for reducing the use of chemicals or implementing a chemical-free insect control is to determine whether insect attack exists and, if so, whether the attack is active. The bamboo should be disposed of or treated with insecticide where necessary, depending on the extent of the insect attack.

Although the feeding biology of D. minutus is highly relevant for establishing high-accuracy detection techniques, as well as other control measures, it remains poorly understood. Because direct, destructive analysis methods may affect the natural growth or behavior of D. minutus, application of non-destructive testing techniques is expected to be a suitable approach to evaluate their feeding.

The authors [4] previously employed X-ray computed tomography $(\mathrm{CT})$ to non-destructively observe the growth process of the larvae and to evaluate their bamboo consumption. However, because of the incapability of continuous monitoring, uncertainty remained regarding the activity of larvae between the scans. Acoustic emission (AE) drew the authors' attention as an approach to monitor the feeding of larvae continuously.

$\mathrm{AE}$ is the phenomenon in which small elastic waves in the ultrasonic frequency range are generated by the release of the stored strain energy when microfractures occur in a material. AE also refers to the elastic waves released by this phenomenon. Fujii et al. [5] reported that AE waves were detected from wood specimens attacked by termites, and Matsuoka et al. [6] directly confirmed that AE events were generated by the feeding activity of termites. Such studies led to the development of AE monitoring as a nondestructive testing technique to detect termite attack in wood and wooden structures [7]. Imamura and Fujii [8] also applied $\mathrm{AE}$ monitoring to the investigation of the feeding responses of termites using $\mathrm{AE}$ event rate as an index of feeding activity. Some studies, though significantly smaller in number than those on termites, deal with $\mathrm{AE}$ generated by wood-boring beetles, such as the powderpost beetle Lyctus brunneus [9, 10], the longhorn beetle species Semanotus japonicus $[9,11]$ and Hylotrupes bajulus [12], and the anobiid beetle species Anobium punctatum, Xestobium rufovillosum [12], and Oligomerus ptilinoides [13]. These previous reports suggested that the feeding activity of $D$. minutus would generate $\mathrm{AE}$ events, and the detection of $\mathrm{AE}$ waves would allow continuous analysis of their feeding that was not accomplished by X-ray CT in the authors' previous study [4], leading to further understanding of the feeding biology.

In order to use $\mathrm{AE}$ monitoring to evaluate the feeding of D. minutus, it is essential to confirm that the beetles' behavior including feeding activity actually produces detectable $\mathrm{AE}$ waves and to clarify the mechanism of $\mathrm{AE}$ generation. Although it was directly confirmed for four termite species that the feeding activity generated $\mathrm{AE}$ events $[6,14,15]$, no studies focused on the direct examination of $\mathrm{AE}$ events generated by beetle species. Therefore, in this study, the behavior of D. minutus, both larvae and adults, on a small bamboo specimen was observed using a microscope camera, while the bamboo specimen attached to an AE sensor was AE-monitored simultaneously. The relation between the movements of the mouthparts, particularly mandibles, of the larvae and adults and the generation of $\mathrm{AE}$ was discussed.

\section{Materials and methods}

\section{Experimental insects and bamboo specimens}

Adult D. minutus were collected from infested bamboo culms in Saitama Prefecture and Oita Prefecture, Japan, and were bred in the laboratory using both artificial diets and bamboo culms, with individuals of the two origins separated. In this experiment, the beetles of different origins were randomly used.

Bamboo specimens $(20 \mathrm{~mm}$ in length and $40 \mathrm{~mm}$ in arc length) were prepared from air-dry culms of madake (Phyllostachys bambusoides Siebold and Zucc.) felled in June 2014 in Kyoto Prefecture, Japan for the observation of larval feeding. The in-curved part near the inner surface of each specimen was shaped into a plane $[20(\mathrm{~L}) \times 28$ (T) $\mathrm{mm}$ ] with a laminate trimmer. A hole with the size of a larva was made with a bit and a chisel in the center of the trimmed plane of each specimen. A D. minutus larva that was estimated to be in the final instar based on its head capsule size was placed in the hole of the specimen, and the hole was covered with a cover glass (Fig. 1).

Bamboo specimens with a different shape from the above-mentioned specimens were used for the observation of adult feeding. This was because an adult beetle would bore in the opposite direction to the microscope lens to avoid the light of the illuminator and it would be

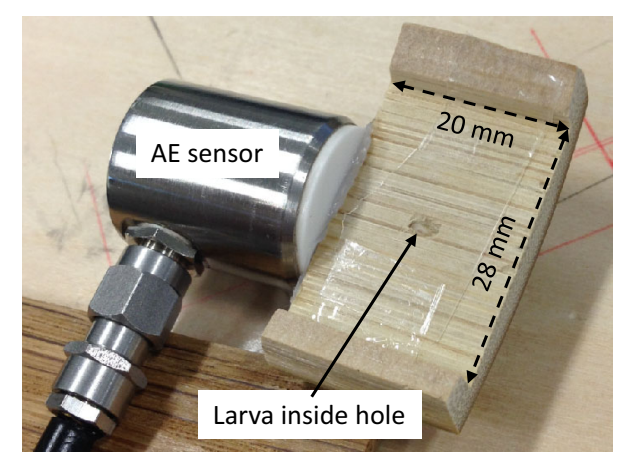

Fig. 1 Bamboo specimen for the observation of larval feeding, attached to the AE sensor 


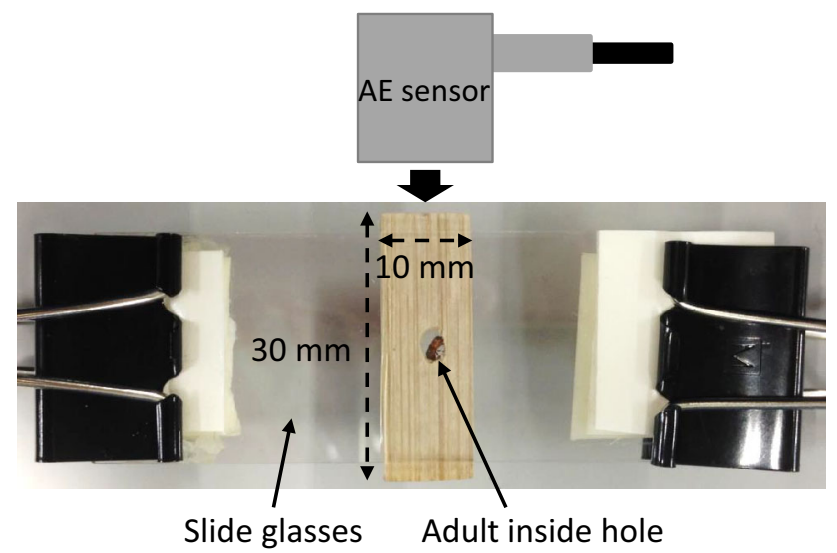

Fig. 2 Bamboo specimen for the observation of adult feeding

impossible to observe the mouthparts. The specimens, sheet shaped with the dimension of $30(\mathrm{~L}) \times 10(\mathrm{~T}) \times 1.5$ (R) $\mathrm{mm}$, were prepared from the air-dry madake culms. A hole with the size of an adult was drilled through the center of the LT plane of each specimen with a bit. An adult, shortly after eclosion from pupa, was placed in this hole, and then the specimen was fixed between two microscope slides with binder clips (Fig. 2).

\section{Apparatuses}

Some larvae or adults immediately began chewing the specimen after they were placed in the specimen; others were left still for as long as overnight to wait for chewing behavior to be observed. When the larva or adult began chewing the bamboo specimen, the AE sensor (R15 $\alpha$, Physical Acoustics Co., USA) with a resonant frequency of $150 \mathrm{kHz}$ was attached to the end surface of the specimen which was closer to the beetle's mouthparts than the other. This type of sensors was chosen because the use of sensors with resonant frequencies of $140-150 \mathrm{kHz}$ has been common in the AE detection of insects [5-11, 14, 15]. A silicone grease was applied as an acoustic couplant between the specimen and the sensor. Because the sensor was insensitive to airborne noise, no sound-proof box was used in this experiment. The sensor was connected to the PC via an AE tester (AE9501A, NF Co., Japan) and a PC-oscilloscope (DSO-2090 USB, Qingdao Hantek Electronic Co., Ltd., China). The AE signals from the sensor were amplified by 40 times and filtered by a high-pass filter with the cut-off frequency of $100 \mathrm{kHz}$. The signal waveform was acquired every time a trigger occurred and was displayed on the PC screen in real time. Because the trigger level was not constant, the threshold that defines an AE hit was later determined at $20.5 \mathrm{mV}$. Therefore, a signal that exceeded $20.5 \mathrm{mV}$ was counted as an AE hit. The amplitude display range was $398 \mathrm{mV}$, meaning that parts of the waveforms

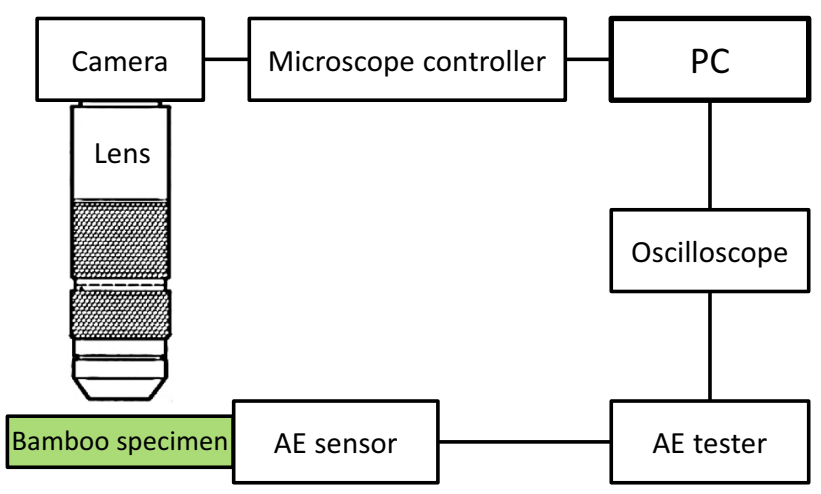

Fig. 3 Schematic diagram of the experimental system

that exceeded this range would not be displayed or measured.

The larva or adult in the specimen was observed by the microscope (VH-5000, Keyence Co., Japan), and the video images were displayed on the PC screen in real time with a resolution of $640 \times 480$ pixels. The $\mathrm{AE}$ waveforms and video images were recorded by a screen capturing software (AG-desktop recorder Ver. 1.2.2, T. Ishii) with a frame rate of $16 \mathrm{fps}$. The experimental set-up is summarized in Fig. 3. The experiment was conducted in the laboratory at a temperature of $25^{\circ} \mathrm{C}$. Four different individual larvae and three different individual adults were used for observation and analysis.

A control specimen with no beetle was also used for AE measurement to examine the presence of noise signals. The number of $\mathrm{AE}$ hits detected from the control specimen within $150 \mathrm{~s}$ of measurement was $0-3$, suggesting that the noise signals would hardly affect the results of the experiment.

\section{Measurement of time lags between AE signals and video signals}

Possible time lags between AE signals and video signals displayed on the PC screen in this experimental system were measured using the pencil lead break as a simulated AE source. The method of the pencil lead break was based on NDIS 2110 [16]. A bamboo specimen (10 $\mathrm{mm}$ in length and $40 \mathrm{~mm}$ in arc length) was prepared from the air-dry madake culm. The AE sensor was fixed with the piezoelectric face facing up, and the specimen was vertically placed on the piezoelectric face with the silicone grease couplant. The pencil lead break was performed 6 times on the end surface of the specimen, and this process was filmed by the microscope camera, with the lens fixed horizontally. On the PC screen, AE signal waveforms and video images were displayed and captured. As a result, the first frame capturing the broken lead appeared 1-2 frames 
(1.5 frames on average) after the first frame capturing the waveform originating from the pencil lead break appeared. Therefore, when an AE waveform was detected in a frame of the analyzed video clip of $D$. minutus feeding, the next frame or the frame after next was assumed to show the microscope image of the moment of AE generation.

\section{Analysis}

The behavior of the larvae and adults was separated into "chewing" and "non-chewing." When the beetle applied its open mandibles to the bamboo specimen, brought them together medially, and reopened them, we defined such movement of the mandibles as a "chewing movement." Any movement of the mandibles in which the mandibles never touched the specimen was not regarded as a chewing movement. Parts of the video clips in which the mandibles were unclearly observed were not used for analysis. Figure 4 shows the relation of the number of AE hits detected in the "chewing phases" observed in a video clip to the length of the chewing phases. The number of the chewing movements of the mandibles in each video clip was
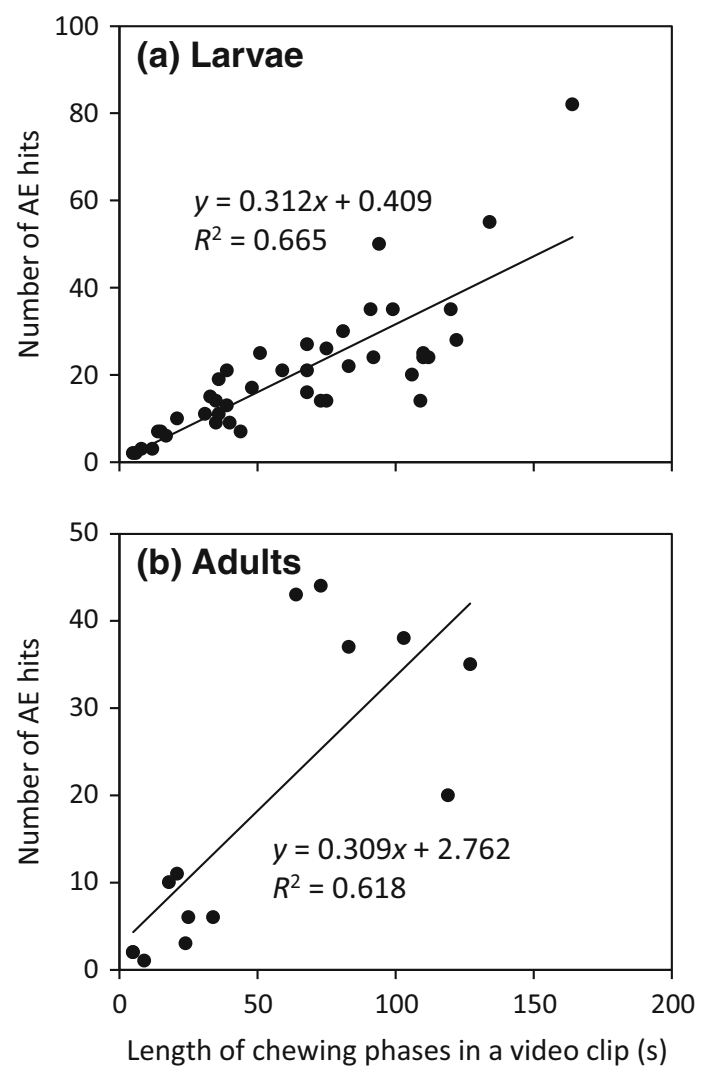

Fig. 4 Relationship between the number of AE hits detected in the chewing phases observed in each video clip and the length of the chewing phases. Different individuals are not distinguished in this figure counted by visual observation, and the detection of $\mathrm{AE}$ hit(s) was examined in each chewing movement. To support the results of the observation, example video clips (Online Resources 1-4) were appended as electronic supplementary materials in this paper.

\section{Results and discussion}

\section{Larval feeding}

In the "chewing phases," the larval mandibles were almost constantly in chewing movements. Table 1 shows the number of chewing movements of the mandibles and the number of AE hits detected in the chewing phases of the four larvae. The number of chewing movements observed in the total analysis time $T$ (s) is indicated by $n$ in Table 1 . There were two types of chewing movements: those in which one or more AE hits were detected and those in which no AE hits were detected. The former is referred to as "AE-generating chewing movements" and the number of them is indicated by $m$. The total number of AE hits detected in $T$ is indicated by $a$.

Signals of burst AE were detected in the AE-generating chewing movements of the mandibles, as shown in the video clip of Larva I (Online Resource 1), and the number of detected AE hits in the chewing phases was significantly larger than the possible number of noise signals. The AE waveforms contained the principal frequency component corresponding to the resonant frequency of the sensor, $150 \mathrm{kHz}$, although a wide range of frequencies was estimated to be produced. Figure 5 shows an example series of successive frames of the video clip (Online Resource 1) capturing the moment of $\mathrm{AE}$ detection and a chewing movement of the mandibles. The mandibles of the larva gradually came together from the first frame (Fig. 5a) to the sixth frame (Fig. 5f). A newly detected AE waveform appears in the third frame (Fig. 5c). Since the video signals were delayed from the AE signals by 1-2 frames, the mandibles are estimated to have triggered the $\mathrm{AE}$ event in the fourth frame (Fig. 5d) or fifth frame (Fig. 5e).

Table 1 and Online Resource 1 also show that AE hits were not always detected in every chewing movement. The ratio of AE-generating chewing movements $m / n$ was smaller than 0.5 for any larva (Table 1), implying that the majority of chewing movements did not produce detectable AE hits. However, all AE hits were detected when the mandibles were in chewing movements, suggesting that $\mathrm{AE}$ waves were generated by the chewing movements of the mandibles. When no $\mathrm{AE}$ hit was detected in a chewing movement, the chewing movement may have produced AE signals that did not exceed the threshold level. This should be examined in a new 
Table 1 Relation between the number of chewing movements of mandibles and AE hits detected in the chewing phases of the larvae

\begin{tabular}{|c|c|c|c|c|c|c|c|}
\hline Larva & $\begin{array}{l}\text { Number of } \\
\text { chewing } \\
\text { movements } n\end{array}$ & $\begin{array}{l}\text { Number of AE- } \\
\text { generating chewing } \\
\text { movements } m\end{array}$ & $\begin{array}{l}\text { Ratio of AE- } \\
\text { generating chewing } \\
\text { movements } m / n\end{array}$ & $\begin{array}{l}\text { Number of AE hits } \\
\text { generated in chewing } \\
\text { movements } a\end{array}$ & $\begin{array}{l}\text { AE hits per } \mathrm{AE}- \\
\text { generating chewing } \\
\text { movement } a / m\end{array}$ & $\begin{array}{l}\text { Total } \\
\text { analysis } \\
\text { time } T(\mathrm{~s})\end{array}$ & $\begin{array}{l}\text { Chewing } \\
\text { movements } \\
\text { per second } n / T\end{array}$ \\
\hline I & 1229 & 316 & 0.26 & 349 & 1.1 & 1461 & 0.84 \\
\hline II & 593 & 212 & 0.36 & 268 & 1.3 & 646 & 0.92 \\
\hline III & 180 & 76 & 0.42 & 88 & 1.2 & 219 & 0.82 \\
\hline IV & 292 & 117 & 0.40 & 148 & 1.3 & 352 & 0.83 \\
\hline
\end{tabular}

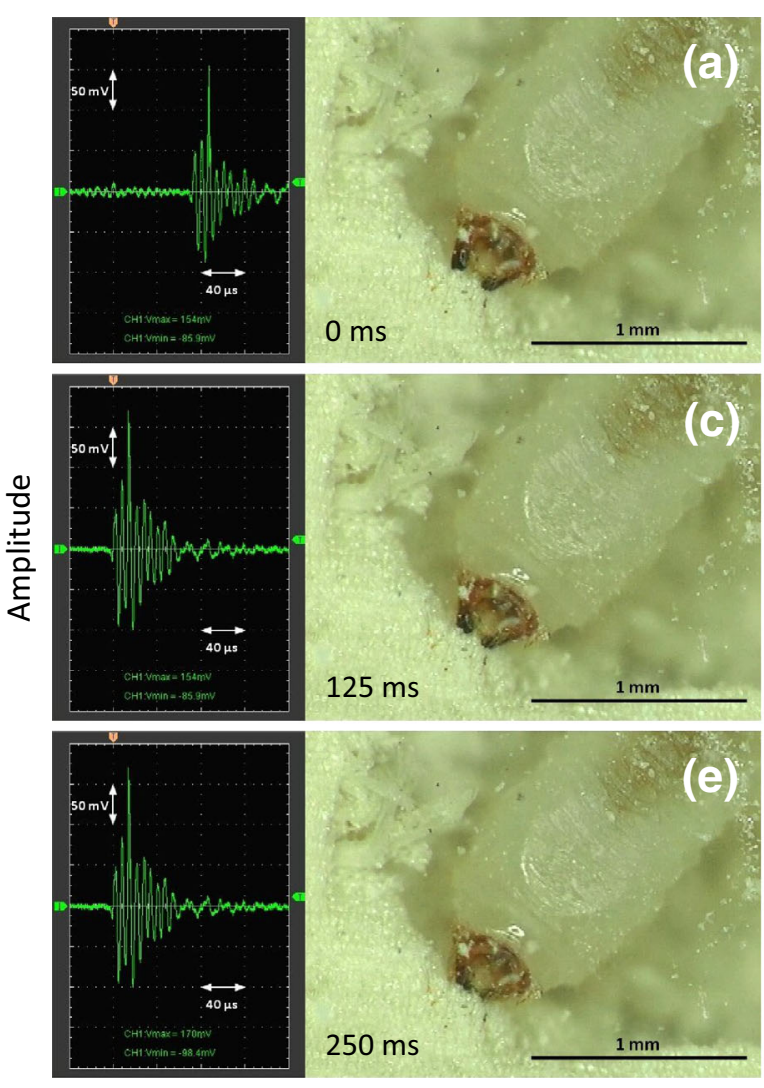

Time
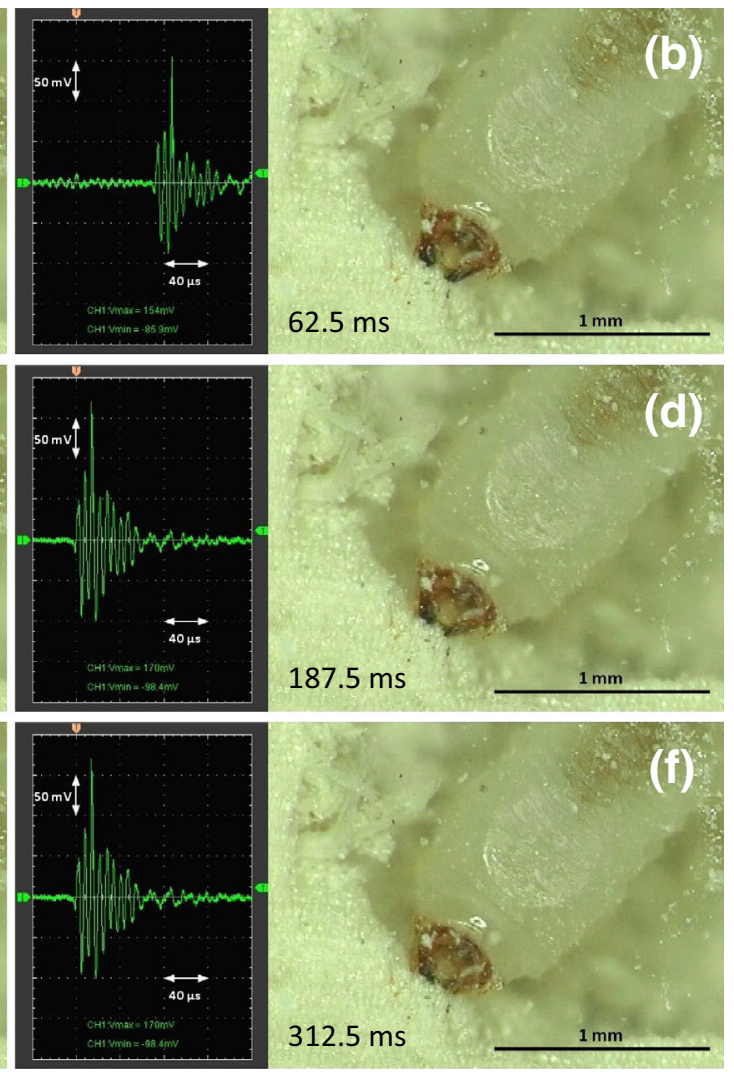

Time

Fig. 5 Series of frames of the video clip (Online Resource 1) capturing the moment of $\mathrm{AE}$ detection and a chewing movement of the mandibles of Larva I. Each frame consists of the waveform of the

experiment with different signal amplifications. Additionally, the possibility cannot be denied that the authors regarded a movement in which the mandibles never touched the specimen as a chewing movement.

One AE-generating chewing movement usually produced one AE hit. However, the ratio of detected AE hits to the number of AE-generating chewing movements $a / m$ is greater than 1 (Table 1). This is because more than one hit was detected in some of the chewing movements, as shown in the distribution of the number of $\mathrm{AE}$ hits detected in one AE-generating chewing movement of Larva I (Fig. 6). For
AE signal (left) and the microscope image of the larva (right). Note that both the waveforms and the microscope images in the video clip have been cropped from the original video

example, a chewing movement in which three AE hits were detected is observed at around $15 \mathrm{~s}$ of the video clip (Online Resource 1). In some cases, the later AE wave had smaller amplitude than the earlier wave and the later wave seemed like the reflection components of the earlier wave. However, the velocities of $\mathrm{AE}$ waves propagating through madake culms measured preliminarily by the authors suggested that the reflection components would appear in the same frame as the original wave under the measurement conditions employed. Therefore, when more than one AE hit was detected in a chewing movement, the movement 


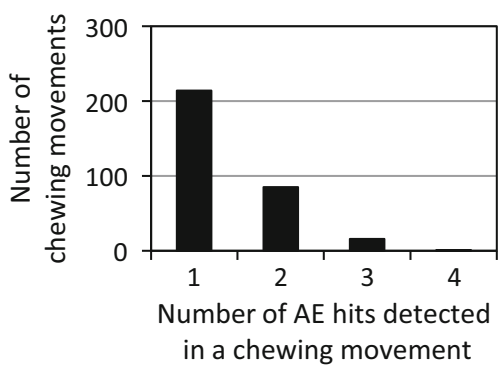

Fig. 6 Distribution of the number of AE hits detected in one chewing movement of Larva I

Table 2 Number of AE hits detected in the non-chewing phases of the larvae

\begin{tabular}{lcl}
\hline Larva & Total analysis time (s) & Number of AE hits \\
\hline I & 181 & 1 \\
II & 93 & 0 \\
III & 141 & 0 \\
IV & 150 & 0 \\
\hline
\end{tabular}

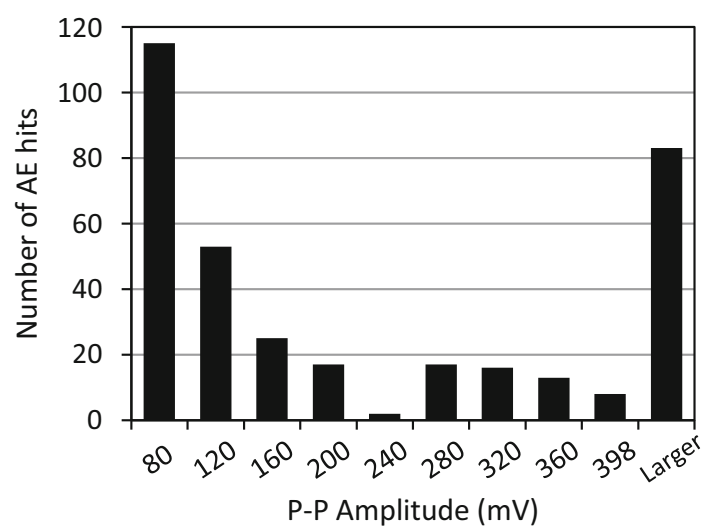

Fig. 7 P-P amplitude distribution of AE hits detected in the chewing phases of Larva I

produced more than one $\mathrm{AE}$ event. The reasons of this were considered, but were not clarified.

An example video clip of the "non-chewing phase" of Larva I is shown in Online Resource 2. In this video clip, although the larval body was moving, no chewing movements of the larval mandibles were observed, and no AE hits were detected. Table 2 shows the lengths of the nonchewing phases and the number of $\mathrm{AE}$ hits detected in these phases. Only one hit was detected in the analyzed non-chewing phases. This concluded that almost all AE hits detected in the chewing phases were produced by the chewing movements of the mandibles.

Figure 7 shows the distribution of the peak-to-peak ( $\mathrm{P}-$ $\mathrm{P})$ amplitude of the $\mathrm{AE}$ hits detected in the chewing phases of Larva I. The P-P amplitude values of detected AE hits varied greatly, and on average, $21 \%$ of the hits detected from all larvae had P-P amplitude values that were larger than the display range of $398 \mathrm{mV}$. It is reported that the amplitude values of AE waves produced by termite species differed among the types of feeding behavior and "pulling" behavior produced largest amplitude [6, 15]. However, in this experiment, no specific pattern of chewing movements was observed in the behavior of $D$. minutus larvae, when the P-P amplitude values of AE hits were relatively large. The amplitude may have depended on the types of bamboo tissue, with different physical or mechanical properties, that were being bitten at or off by the larva. The occurrence of $\mathrm{AE}$ waves that have large amplitude is crucial in the practical application of $\mathrm{AE}$ detection because $\mathrm{AE}$ waves with smaller amplitude would not be detected owing to the attenuation in the long bamboo culm.

The fragments that were bitten off by the larvae were difficult to observe. However, Larva II actually consumed a part of the specimen near its head and particles of excreta were produced near its abdomen within $4 \mathrm{~h}$ (Fig. 8), and this suggested that the chewing behavior discussed thus far was certainly feeding behavior. This also suggests that larval frass of $D$. minutus consists mostly of excrement. It

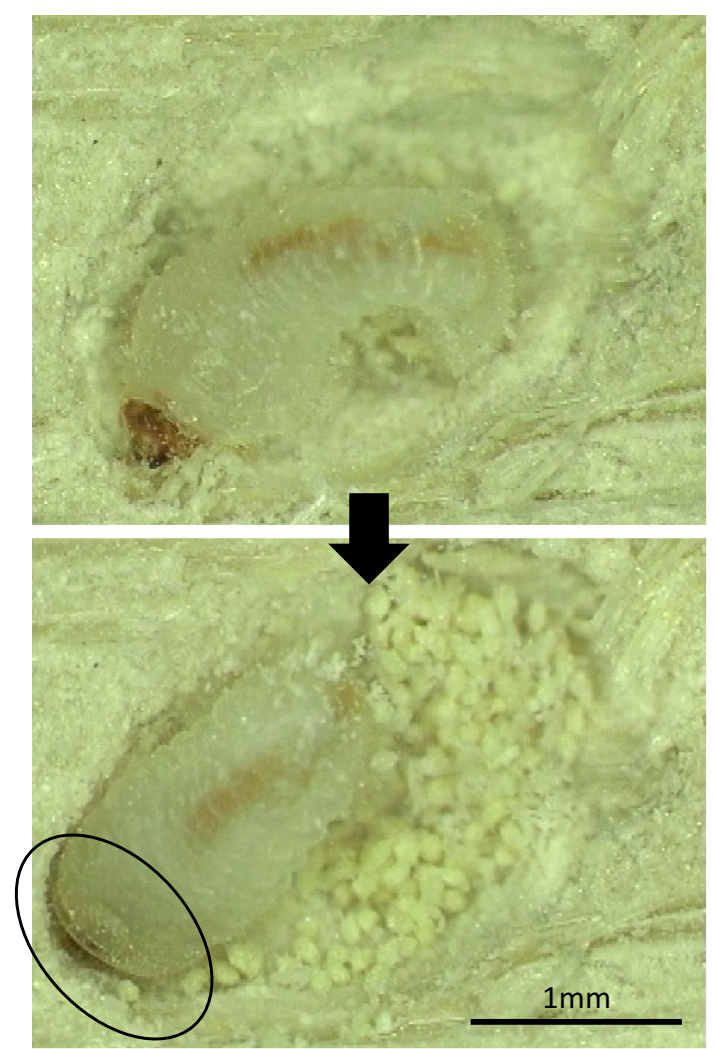

Fig. 8 Part of the bamboo specimen marked with an oval was consumed by Larva II and particles of larval excreta were produced within $4 \mathrm{~h}$ 
should be noted that, in contrast to workers or pseudergates of termites which can pull wood fragments off with the aid of their legs as props [15], the short larval legs of $D$. minutus appear to have no such function. Although the observed larvae sometimes seemed to be pulling bamboo fragments after they brought the mandibles together by slightly withdrawing the head, the removal of bamboo fragments was estimated to rely mostly on the to-and-fro chewing movements of the mandibles.

From the above results, it was directly confirmed that the feeding behavior of the larvae triggered the generation of AE events. Therefore, AE monitoring can be applied to the continuous analysis of the feeding of $D$. minutus larvae.

\section{Adult feeding}

An example video clip of the chewing phase of Adult I is shown in Online Resource 3. Figure 9 shows an example frame of the video clip (Online Resource 3). The adults had larger mandibles than the larvae. The movements of adult mandibles were similar to those of the larvae, and the video clips were analyzed in the same manner. Table 3 shows the number of chewing movements of the mandibles and the number of $\mathrm{AE}$ hits detected in the chewing phases of the three adults. AE hits were detected in the chewing phases as the adult chewed the specimen with its mandibles. As in larval chewing movements, AE hits were not always detected in every chewing movement, and the ratio of AE-
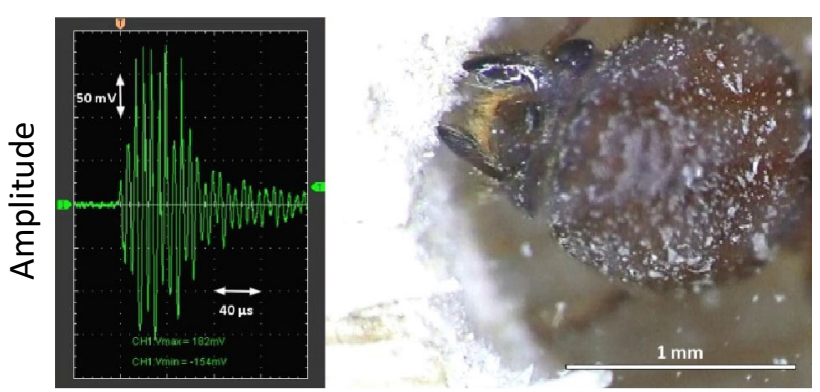

Time
Fig. 9 Frame of the video clip (Online Resource 3) of Adult I. Left waveform of the AE signal, right microscope image. Note that both the waveforms and the microscope images in the video clip have been cropped from the original video
Table 4 Number of AE hits detected in the non-chewing phases of the adults

\begin{tabular}{lcl}
\hline Adult & Total analysis time (s) & Number of AE hits \\
\hline I & 36 & 0 \\
II & 28 & 0 \\
III & 131 & 0 \\
\hline
\end{tabular}

generating chewing movements to all chewing movements $m / n$ was $27-43 \%$ (Table 3 ). However, all AE hits were detected when the mandibles were in chewing movements. One AE-generating chewing movement usually produced one $\mathrm{AE}$ hit, but the ratio of detected $\mathrm{AE}$ hits to the number of AE-generating chewing movements $a / m$ is greater than 1 (Table 3) because more than one hit was detected in some of the chewing movements. The frequency of chewing movements, represented as $n / T$ in Table 3, was similar between the larvae and adults. On average, $19 \%$ of the AE hits detected from the adults had P-P amplitude values larger than $398 \mathrm{mV}$, which is also similar to the case of the larvae. However, the adults with larger mandibles may be able to produce AE waves with larger amplitude than the larvae, although it is unclear from this study. Further comparison between the characteristics of larval and adult feeding should be done in a continuous, long-term AE monitoring in the future.

Table 4 shows the lengths of the non-chewing phases and the number of $\mathrm{AE}$ hits detected in these phases. An example video clip of the non-chewing phase of Adult $\mathrm{I}$ is shown in Online Resource 4. No AE hits were detected in the non-chewing phases. Therefore, AE hits detected from the specimens in the chewing phases were produced by the chewing movements of the mandibles of the adults.

\section{Conclusions}

In this study, the observation of the movements of the mandibles of D. minutus in the bamboo specimen and $\mathrm{AE}$ measurement of the specimen were conducted in real time. It was directly confirmed that the chewing movements of the mandibles of both larvae and adults triggered the generation of $\mathrm{AE}$ events. This result suggests that the

Table 3 Relation between the number of chewing movements of mandibles and AE hits detected in the chewing phases of the adults

\begin{tabular}{|c|c|c|c|c|c|c|c|}
\hline Adult & $\begin{array}{l}\text { Number of } \\
\text { chewing } \\
\text { movements } n\end{array}$ & $\begin{array}{l}\text { Number of AE- } \\
\text { generating chewing } \\
\text { movement } m\end{array}$ & $\begin{array}{l}\text { Ratio of AE- } \\
\text { generating chewing } \\
\text { movements } m / n\end{array}$ & $\begin{array}{l}\text { Number of AE hits } \\
\text { generated in chewing } \\
\text { movements } a\end{array}$ & $\begin{array}{l}\text { AE hits per AE- } \\
\text { generating chewing } \\
\text { movement } a / m\end{array}$ & $\begin{array}{l}\text { Total } \\
\text { analysis } \\
\text { time } T(\mathrm{~s})\end{array}$ & $\begin{array}{l}\text { Chewing } \\
\text { movements } \\
\text { per second } n / T\end{array}$ \\
\hline I & 243 & 86 & 0.35 & 101 & 1.2 & 233 & 1.0 \\
\hline II & 171 & 73 & 0.43 & 83 & 1.1 & 171 & 1.0 \\
\hline III & 243 & 66 & 0.27 & 74 & 1.1 & 306 & 0.79 \\
\hline
\end{tabular}


detection of AE signals reflects the feeding of D. minutus. Therefore, this study supports the potential of AE monitoring as a non-destructive tool to evaluate the feeding of this beetle.

Acknowledgments This work was supported in part by Grants-inAid for Scientific Research (No. 25242032 and No. 26450229) from the Japan Society for the Promotion of Science.

\section{References}

1. Mori H, Arai H (1979) Insect damage in bamboo materials and its prevention (in Japanese). House Househ Insect Pests (1, 2):9-23

2. Yamano K (1969) Kenchiku-konchu-ki (Insect pests of buildings) (in Japanese). Sagami Shobo, Tokyo

3. The Society of House and Household Pests Science, Japan (1995) Kaoku-gaichu-jiten (Encyclopedia of house and household pests) (in Japanese). Inoue Shoin, Tokyo

4. Watanabe H, Yanase Y, Fujii Y (2015) Evaluation of larval growth process and bamboo consumption of the bamboo powderpost beetle Dinoderus minutus using X-ray computed tomography. J Wood Sci 61:171-177

5. Fujii Y, Noguchi M, Imamura Y, Tokoro M (1990) Using acoustic emission monitoring to detect termite activity in wood. Forest Prod J 40(1):34-36

6. Matsuoka H, Fujii Y, Okumura S, Imamura Y, Yoshimura T (1996) Relationship between the type of feeding behavior of termites and the acoustic emission (AE) generation. Wood Res 83:1-7

7. Fujii Y, Yanase Y (2001) Non-destructive evaluation of decay and insect attack in wood using acoustic emission (AE) monitoring and a radar technique. Tools for maintaining wood and outdoor applications. In: Imamura Y (ed) High-performance utilization of wood for outdoor uses. Press-Net, Kyoto, pp 145-160

8. Imamura Y, Fujii Y (1995) Analysis of feeding activities of termites by $\mathrm{AE}$ monitoring of infested wood (in Japanese). Mokuzai Hozon (Wood Prot) 21:61-69

9. Fujii Y, Imamura Y, Shibata E, Noguchi M (1992) Feasibility of $\mathrm{AE}$ (Acoustic Emission) monitoring for the detection of the activities of wood destroying insects.Proc IRG Annu Meet IRG/ WP, Harrogate, UK, 92-2416

10. Imamura Y, Adachi A, Fujii Y (1998) Acoustic emission (AE) detected from wood attacked by powder-post beetles, Lyctus brunneus STEPHENS (in Japanese). Jpn J Environ Entomol Zool 9:98-100

11. Fujii Y, Imamura Y, Shibata E (1994) Detection of acoustic emission (AE) generated by the feeding activity of Semanotus japonicus LACORDAIRE (in Japanese). Jpn J Environ Entomol Zool 6:112-118

12. Creemers JGM (2013) Use of Acoustic Emission (AE) to detect activity of common European dry-woodboring insects: some practical considerations. Proc IRG Annu Meet IRG/WP, Stockholm, Sweden, 13-10803

13. Le Conte S, Vaiedelich S, Thomas J-H, Muliava V, de Reyer D, Maurin E (2015) Acoustic emission to detect xylophagous insects in wooden musical instrument. J Cult Herit 16:338-343

14. Fujii Y, Imamura Y, Yoshimura T (1995) Observation of feeding behavior of termite using $\mathrm{CCD}$ camera and its relation to the generation of acoustic emission (AE). Wood Res 82:47-53

15. Indrayani $Y$, Yoshimura $T$, Yanase $Y$, Fujii $Y$, Matsuoka H, Imamura Y (2007) Observation of feeding behavior of three termite (Isoptera) species: Incisitermes minor, Coptotermes formosanus, and Reticulitermes speratus. Sociobiol 49:121-134

16. NDIS 2110 (1997) Method for measurement of sensitivity degradation of acoustic emission transducer (in Japanese). Japanese Society for Non-Destructive Inspection, Tokyo 